\title{
Self-reported sleep quality and acute exacerbations of chronic obstructive pulmonary disease
}

\author{
This article was published in the following Dove Press journal: \\ International Journal of COPD \\ 20 February 2015 \\ Number of times this article has been viewed
}

\author{
Jeanne Geiger-Brown' \\ Sarah Lindberg ${ }^{2}$ \\ Samuel Krachman ${ }^{3}$ \\ Charlene E McEvoy ${ }^{4}$ \\ Gerard J Criner ${ }^{3}$ \\ John E Connett ${ }^{2}$ \\ Richard K Albert ${ }^{5}$ \\ Steven M Scharf' \\ 'Center for Health Outcomes \\ Research, University of Maryland \\ School of Nursing, Baltimore, \\ MD, ${ }^{2}$ University of Minnesota \\ School of Public Health, Division \\ of Biostatistics, Minneapolis, MN, \\ ${ }^{3}$ Pulmonary and Critical Care \\ Medicine, Department of Medicine, \\ Temple University School of Medicine, \\ Philadelphia, PA, ${ }^{4}$ Health Partners \\ Institute of Education and Research, \\ St Paul, MN, ${ }^{5}$ The Medicine Service, \\ Denver Health and Department \\ of Medicine, the University \\ of Colorado Denver Health Sciences \\ Center, Denver, CO, ${ }^{6}$ Department of \\ Medicine, Pulmonary and Critical Care \\ Division, University of Maryland School \\ of Medicine, Baltimore, MD, USA
}

Correspondence: Steven M Scharf Sleep Disorders Center, University of Maryland, $100 \mathrm{~N}$ Greene Street, 2nd Floor, Baltimore, MD 2120I-I 192, USA

$\mathrm{Tel}+$ I 4I0 706 477I

Fax + I 4107060345

Email sscharf@medicine.umaryland.edu
Background: Many patients with chronic obstructive pulmonary disease (COPD) suffer from poor sleep quality. We hypothesized that poor sleep quality in otherwise stable patients predicted exacerbations in these patients.

Methods: This is a secondary analysis of the results of a previously published randomized trial of azithromycin in 1,117 patients with moderate to severe COPD who were clinically stable on enrollment. Sleep quality was measured using the Pittsburgh Sleep Quality Index. Other quality of life indices included the Medical Outcome Study 36-item Short Form Health Survey and the St Georges Respiratory Questionnaire. Outcomes included time to first exacerbation and exacerbation rate.

Results: Sleep quality was “poor” (Pittsburgh Sleep Quality Index $>5$ ) in 53\% of participants but was not related to age or severity of airflow obstruction. Quality of life scores were worse in "poor" sleepers than in "good" sleepers. Major classes of comorbid conditions, including psychiatric, neurologic, and musculoskeletal disease, were more prevalent in the "poor" sleepers. Unadjusted time to first exacerbation was shorter (190 versus 239 days) and exacerbation rate (1.7 versus 1.37 per year) was greater in the poor sleepers, but no differences were observed after adjusting for medications and comorbid conditions associated with poor sleep.

Conclusion: Poor sleepers had greater exacerbation rates than did good sleepers. This appeared to be due largely to them having more, or more severe, concomitant medical conditions and taking more medications.

Keywords: Pittsburgh Sleep Quality Index, SF-36, St George's Respiratory Questionnaire

\section{Introduction}

Symptom burden in chronic obstructive pulmonary disease (COPD) is closely associated with health-related quality of life (HRQoL) ${ }^{1-6}$ Poor sleep quality is prevalent in these patients and predicts other indices of HRQoL. ${ }^{6-9}$ While physiologic changes in COPD may contribute to nocturnal pulmonary symptoms, ${ }^{6,7,10,11}$ sleep quality is not necessarily related to physiologic disease severity. ${ }^{6}$ In a cohort of 98 patients with COPD, Omachi et al ${ }^{12}$ demonstrated that "disturbed sleep" was a predictor of adverse outcomes, including mortality and exacerbations. In an editorial comment on this paper, Kent et $\mathrm{al}^{13}$ pointed out that the causal pathways were not clear and that severe COPD might be associated with poor outcomes due to worsening physiology or to the presence of concomitant medical conditions.

Recently in a large, well-characterized cohort of patients with moderate to severe COPD, Albert et $\mathrm{al}^{14}$ reported that taking azithromycin daily for one year decreased acute exacerbations. In this randomized controlled trial, data on sleep quality, quality of life, physiologic severity, concomitant medical conditions, and medication use were collected at enrollment and over the one-year course of the trial. In this secondary analysis 
of that study, we aimed to: characterize sleep quality at enrollment when participants were clinically stable; describe the relationships between sleep quality, concomitant medical conditions, and medications; and determine if sleep quality at enrollment was predictive of other indices of HRQoL and/ or was an independent predictor of time to first exacerbation and mortality over the course of the trial. We hypothesized that sleep quality would be poor even in patients with clinically stable COPD, that concomitant medical and psychiatric conditions would be associated with poor sleep quality which would, in turn, be associated with worse HRQoL, and that poor sleep quality at study enrollment would be associated with having more frequent exacerbations, possibly due to the associated burden of concomitant disease.

\section{Materials and methods}

\section{Sample and design}

Details of the parent study are described elsewhere. ${ }^{14}$ Briefly, patients were aged $\geq 40$ years, had moderate to severe COPD assessed by spirometry, and were considered to be at increased risk of having an exacerbation over the one-year course of the trial. The primary outcome variable was time to first exacerbation from enrollment. Participants had to be exacerbation-free and medically stable for at least 4 weeks prior to trial enrollment. Data were collected at enrollment and at 3 and 12 months following enrollment. Only participants with follow-up data after randomization were included in this secondary analysis $(n=1,117)$. This study was conducted in accordance with the amended Declaration of Helsinki. Local institutional review boards from each participating site approved the protocol, and written informed consent was obtained from all participants. Permission was obtained as required for the use of all instruments in this study, which is registered at ClinicalTrials.gov as NCT00325897.

\section{Measures}

\section{Sleep quality}

Self-reported sleep quality was measured using the Pittsburgh Sleep Quality Index (PSQI). ${ }^{15}$ Scale items include subjective sleep quality, sleep duration, use of sleep aids, self-estimated sleep efficiency, disturbances, and daytime dysfunction. Scores range from 0 to 21, with higher scores reflecting poorer sleep quality. "Good" sleep was defined as a PSQI $\leq 5$ and poor sleep as PSQI $>5 .{ }^{15}$

\section{Patient factors}

Spirometric indices were measured, and the Global Initiative for Obstructive Lung Disease class (II-IV) was assessed. ${ }^{16}$

\section{Treatment factors}

Self-reported concomitant medication classes and medical comorbidities were coded as present or absent. Pulmonary treatment factors included oxygen use and inhaled medications (corticosteroids, long-acting beta-agonists, long-acting muscarinic antagonists). Other medications were classified into descriptive groups. ${ }^{17}$

\section{Outcome variables}

Time to first exacerbation was the primary outcome variable. Exacerbations were defined as increased respiratory symptoms for more than 3 days of more than one of the following: cough, sputum, wheezing, dyspnea, or chest tightness requiring treatment with antibiotics and/or systemic steroids. ${ }^{18}$

We also recorded other HRQoL indices, including the Medical Outcome Study 36-item Short Form Health Survey $(\mathrm{SF}-36)^{19}$ and a disease-specific quality of life (DSQoL) survey, the St George's Respiratory Questionnaire. ${ }^{20,21}$ The SF-36 includes eight subscales: physical functioning, rolephysical, role-emotional, vitality, mental health, social functioning, bodily pain, and general health (range 0-100, with a higher score indicating less disability). The St George's Respiratory Questionnaire score includes three subscales: symptoms, activity, and overall impact, ranging from $0 \%$ (best) to $100 \%$ (worst).

\section{Data analysis}

The data are presented as the mean \pm standard deviation if normally distributed and as the median with 95\% confidence interval if non-normally distributed and proportions as appropriate. Comparisons of mean levels of quantitative variables between groups were assessed using unpaired $t$-tests. Proportions were compared between groups using chi-square testing. The association of sleep quality at baseline with time to first exacerbation was assessed using a Cox regression with adjustment for age, sex, concomitant medical/psychiatric disease, and concomitant medication class: Changes in PSQI over time were analyzed using mixed models two-factor analysis of variance. The null hypothesis was rejected at the $5 \%$ level.

\section{Results}

\section{Sleep quality and association with patient and treatment factors}

The mean baseline PSQI was 6.6 \pm 4.2 (range 0-20), with poor sleep quality (PSQI $>5$ ) in 53\% of the sample. One third of participants reported sleep latency $>30$ minutes, $20 \%$ reported sleeping $<6$ hours per night, $20 \%$ took sleep aids at least three 
times a week, and sleep efficiency was $<85 \%$ in $40 \%$. Despite self-reported poor sleep quality, only $21 \%$ reported that daytime dysfunction was "somewhat of" or a "big" problem.

\section{Age, pulmonary function, and quality of life indices}

Table 1 shows the mean age, pulmonary function, and HRQoL indices in patients with PSQI scores $\leq 5$ and $>5$. Patients with PSQI $\leq 5$ ("good" sleepers) were somewhat older, and both DSQoL (St George's Respiratory Questionnaire) and HRQoL (SF-36 domains) were better than those with PSQI >5 ("poor" sleepers). No difference was observed in indices of pulmonary function or Global Initiative for Obstructive Lung Disease classification (not shown) between the two groups. Females had somewhat higher PSQI scores than males $(7.0 \pm 4.3$ versus $6.3 \pm 4.0$, respectively; $P<0.01)$.

\section{Medical comorbidities and concomitant medication use}

Table 2 shows the major classes of concomitant medical/ psychiatric conditions evaluated. Concomitant neurologic, musculoskeletal, and all categories of psychiatric disease were more common in participants with PSQI $>5$. Regarding cardiovascular disease, the prevalence of heart attack/ angina, congestive heart failure, and poor circulation was greater among those with PSQI $>5$. However, no difference was observed in the overall prevalence of all cardiovascular diseases between those with PSQI $\leq 5$ and those with PSQI $>5$. Two hundred and forty-seven $(22.1 \%)$ participants reported concomitant obstructive sleep apnea. However, no difference was observed in PSQI between those with and those without obstructive sleep apnea. The proportions of participants on various classes of inhaled pulmonary treatments and oxygen are listed in Table 3. None were significantly associated with a difference in PSQI compared with participants not using the listed treatments. Table 4 shows the use of various major classes of noninhaled medications in participants with PSQI $\leq 5$ and those with PSQI $>5$ for which statistical significance was found. No significant difference was observed between good and poor sleepers and the use of other drug classes. The table also shows that randomization to the study drug was not associated with different baseline (prerandomization) difference in sleep quality.

\section{Exacerbations and mortality}

Table 5 presents data on exacerbations. Time to first exacerbation was shorter in patients with PSQI $>5$ compared with those with PSQI $\leq 5$, both unadjusted and adjusted for age and sex. However, after further adjustment for medication classes and concomitant diseases, no significant difference in time to first exacerbation between the groups was observed. Figure 1 shows the unadjusted time to first exacerbation in good and poor sleepers presented as a survival curve. Similarly, the mean exacerbation rate over the one-year study period (exacerbations per year) was lower in participants with PSQI $\leq 5$ than in those with PSQI $\leq 5$ before and after adjusting for age and sex. However, when adding adjustment for medication and disease classes, no significant difference was observed. Thirty-six patients (3.2\%) died over the course of the study. Twenty-three of these had PSQI

Table I Baseline characteristics

\begin{tabular}{|c|c|c|}
\hline $\begin{array}{l}\text { Age, spirometry, and QoL } \\
\text { on enrollment (mean } \pm \text { SD) }\end{array}$ & $\begin{array}{l}\text { PSQI }<5 \text { on } \\
\text { enrollment }(n=5 \mid 3)\end{array}$ & $\begin{array}{l}\text { PSQI }>5 \text { on } \\
\text { enrollment }(n=58 I)\end{array}$ \\
\hline Age & $66.6 \pm 8.2$ & $63.9 \pm 8.8^{*}$ \\
\hline $\mathrm{FEV}_{\mathrm{I}}$ (\% predicted) & $38.96 \pm 15.56$ & $40.04 \pm 15.59$ (NS) \\
\hline $\mathrm{FEV}, / \mathrm{FVC}(\%)$ & $41.8 \pm 12.5$ & $43.1 \pm 12.9$ (NS) \\
\hline SGRQ global score & $44.4 \pm 14.9$ & $55.7 \pm 15.7 *$ \\
\hline \multicolumn{3}{|l|}{ SF-36 domains I-8 } \\
\hline Physical function & $42.2 \pm 24.0$ & $32.6 \pm 22.6 *$ \\
\hline Role physical & $44.1 \pm 39.9$ & $26.4 \pm 36.1 *$ \\
\hline Role emotional & $77.1 \pm 36.5$ & $60.8 \pm 42.7^{*}$ \\
\hline Vitality & $54.7 \pm 20.7$ & $41.5 \pm 18.8 *$ \\
\hline Emotional well & $81.0 \pm 14.7$ & $69.8 \pm 19.4^{*}$ \\
\hline Social function & $79.0 \pm 22.6$ & $62.8 \pm 27.3^{*}$ \\
\hline Pain & $77.4 \pm 23.0$ & $62.1 \pm 27.4^{*}$ \\
\hline General health & $45.6 \pm 21.6$ & $35.1 \pm 18.7^{*}$ \\
\hline
\end{tabular}

Note: $* P<0.0001$.

Abbreviations: PSQI, Pittsburgh Sleep Quality Index; FEV , forced expired volume in one second; FVC, forced vital capacity; NS, not statistically significant; QoL, quality of life; SGRQ, St George's Respiratory Questionnaire (lung disease-specific quality of life); SF-36, Medical Outcomes Short Form 36 (general quality of life); SD, standard deviation. 
Table 2 Major classes of concomitant medical/psychiatric conditions at baseline associated with worse sleep quality

\begin{tabular}{|c|c|c|}
\hline Disease class, $\mathbf{n}(\%)$ & $\begin{array}{l}\text { PSQI } \leq 5 \text { on } \\
\text { enrollment }(n=5 \mid 3)\end{array}$ & $\begin{array}{l}\text { PSQI }>5 \text { on } \\
\text { enrollment }(n=58 I)\end{array}$ \\
\hline Baseline history of & $\mathrm{n}(\%)$ & $\mathrm{n}(\%)$ \\
\hline Cardiovascular disease (all) & $380(74)$ & 439 (76) (NS) \\
\hline High blood pressure & $279(54)$ & 299 (5I) (NS) \\
\hline Coronary artery disease & $89(17)$ & II 4 (20) (NS) \\
\hline Angina/heart attack & $97(19)$ & $170(29)^{*}$ \\
\hline Murmur & $35(7)$ & 49 (8) (NS) \\
\hline Palpitations, irregular heartbeat & $87(17)$ & 98 (I7) (NS) \\
\hline Valve disease & $21(4)$ & $33(6)(N S)$ \\
\hline Congestive heart failure & $37(7)$ & $69(12)^{+}$ \\
\hline Blood clots & $39(8)$ & 46 (8) (NS) \\
\hline Poor circulation (claudication) & $49(10)$ & $90(15)^{+}$ \\
\hline Other cardiovascular & $40(8)$ & 46 (8) (NS) \\
\hline GI disease (all) & $324(63)$ & 397 (68) (NS) \\
\hline Neurologic disease (all) & $117(23)$ & $172(30)^{\#}$ \\
\hline Musculoskeletal disease (all) & $354(69)$ & $462(80)^{*}$ \\
\hline \multicolumn{3}{|l|}{ Psychiatric disease } \\
\hline Depression & $99(19)$ & $187(32)^{*}$ \\
\hline Anxiety & $127(25)$ & $254(44)^{*}$ \\
\hline Other & $15(3)$ & $37(6)^{+}$ \\
\hline
\end{tabular}

Notes: Number and proportion of participants with certain major disease classes in good and poor sleepers. Disease categories not associated with differences in sleep quality included cardiovascular and Gl disease. Neurologic disease included stroke, headaches, seizure, and other. Musculoskeletal disease included rheumatoid arthritis, gout, osteoporosis, fractures, joint pain, and osteoarthritis. Although for the overall category "cardiovascular disease", the difference in incidence between good and poor sleepers was NS, certain subcategories of cardiovascular disease showed great proportions among poor sleepers. The table shows all of the cardiovascular disease categories. ${ }^{*} P<0.05,{ }^{+} P<0.01 ; * P<0.0001$.

Abbreviations: GI, gastrointestinal; NS, not statistically significant; PSQI, Pittsburgh Sleep Quality Index.

$>5$ at baseline, while 13 had PSQI $\leq 5$ (odds ratio for poor sleepers of dying 1.56; confidence interval 0.79-3.56). No significant difference in mortality between good and poor sleepers was observed.

\section{Sleep quality over time}

Mean ( \pm standard deviation) PSQI values at baseline, 3 months, and 12 months, respectively, were $6.60 \pm 4.28$,

Table 3 Pulmonary treatments

\begin{tabular}{ll}
\hline Characteristic & $\mathbf{n}(\%)$ \\
\hline Oxygen use at home, $\mathrm{n}(\%)$ & $66 \mathrm{I}(59.3)$ \\
Hours of oxygen/day, mean (SD) & $15.4(8.4)$ \\
Inhaled medications, $\mathrm{n}(\%)$ & \\
Glucocorticoids only & $57(5.1)$ \\
LABAs only & $21(1.9)$ \\
LAMAs only & $77(6.9)$ \\
Glucocorticoids and LABAs & $229(20.5)$ \\
Glucocorticoids and LAMAs & $5 \mathrm{I}(4.6)$ \\
LABAs and LAMAs & $53(4.7)$ \\
Glucocorticoids, LABAs and LAMAs & $528(47.3)$ \\
No inhaled medications & $10 \mathrm{I}(9.0)$ \\
\hline
\end{tabular}

Notes: Number and percent of participants using specific classes of inhaled medications. Oxygen use per day is expressed as mean (SD) hours. The rest are expressed as number (percent of total). None of these inhaled treatments was associated with PSQI that was significantly different for participants using it versus those not using it.

Abbreviations: LABA, long-acting beta agonist; LAMA, long-acting muscarinic agonist; PSQI, Pittsburgh Sleep Quality Index; SD, standard deviation.
$6.64 \pm 4.10$, and $6.67 \pm 4.13$ in the placebo group and $6.62 \pm 4.05,6.28 \pm 4.02$, and $6.05 \pm 3.91$ in the azithromycin group. No significant differences were observed between the groups or over time.

\section{Discussion}

Sleep quality was poor in a substantial proportion of patients and was stable over the course of the trial despite the fact that azithromycin reduced exacerbations. There are a number of medical and psychiatric comorbidities often associated with COPD contributing to poor sleep quality. Indices of HRQoL and DSQoL were worse in those with poor sleep (PSQI >5) than in those with good sleep (PSQI $\leq 5$ ). Patients with good sleep quality had a greater time to first exacerbation compared with those with poor sleep quality. In the ensuing discussion, we consider these findings in light of the currently available literature.

\section{Sleep quality in COPD}

To our knowledge, this is one of the largest, well-characterized COPD cohorts with data on sleep quality. Our findings are consistent with those of others demonstrating a high prevalence of sleep disturbances in COPD..$^{3-6}$ In spite of a high prevalence of poor sleep quality, only $21 \%$ of patients reported daytime dysfunction due to sleepiness. This may 
Table 4 Concomitant use of noninhaled medications in good and poor sleepers

\begin{tabular}{lll}
\hline Medication class, $\mathbf{n}(\%)$ & $\begin{array}{l}\text { PSQI } \leq \mathbf{5} \text { on } \\
\text { enrollment }(\mathbf{n}=\mathbf{5} \mid \mathbf{3})\end{array}$ & $\begin{array}{l}\text { PSQI }>\mathbf{5} \text { on } \\
\text { enrollment }(\mathbf{n}=\mathbf{5 8} \mathbf{I})\end{array}$ \\
\hline Antidepressants & $1 / 4(22)$ & $230(40)^{*}$ \\
Antipsychotics & $7(1)$ & $25(4)^{+}$ \\
Anxiolytics & $52(10)$ & $117(20)^{*}$ \\
Hypnotics & $16(3)$ & $54(9)^{*}$ \\
Anti-seizure medications & $32(6)$ & $60(10)^{\#}$ \\
Opioids & $45(9)$ & $107(18)^{*}$ \\
Dopaminergics & $8(2)$ & $20(3)^{\#}$ \\
Randomized to active drug & $257(50)$ & $289(50)(\mathrm{NS})$ \\
\hline
\end{tabular}

Notes: ${ }^{P} P<0.05 ;{ }^{+} P<0.01 ; * P<0.0001$.

Abbreviations: NS, not statistically significant; PSQI, Pittsburgh Sleep Quality Index.

seem surprising given the prevalence of poor sleep scores, low sleep durations, and prolonged sleep latencies. Possibly, participants under-reported the extent to which they had poor daytime function due to nocturnal sleep problems. Alternatively, the items in the PSQI may be inadequate to capture daytime dysfunction in this population, as participants may be homebound, anxious, and/or depressed. These factors could reduce social activities or impair a participant's ability to measure daytime function. Scharf et al also reported a low incidence of daytime sleepiness in spite of a high incidence of poor sleep quality. ${ }^{6}$ They speculated that COPD patients may be "hyper-alert" because of heightened sympathetic activity, medication effects, and/or anxiety. Future studies should use objective testing to determine if patients with stable COPD have neurocognitive deficits commonly associated with chronic sleep deprivation, or are indeed "hyper-alert".

Indices of airflow obstruction were not significantly different between good and poor sleepers. While this may seem surprising, patients were preselected to have airflow obstruction as measured on spirometry..$^{14} \mathrm{~K}$ won et a ${ }^{10}$ reported that hyperinflation was associated with worse sleep efficiency in patients with concomitant COPD and obstructive sleep apnea. In the present study, lung volumes were not measured and we cannot determine if hyperinflation was a physiologic factor associated with worse sleep quality.

Certain comorbid conditions were associated with poor sleep quality, including certain types of cardiovascular disease (although the category as a whole was not associated with sleep quality), as were gastrointestinal, neurologic, musculoskeletal, and all categories of psychiatric disease. This is not surprising, as these categories of disease are associated with physical or psychologic discomfort and are known to lead to insomnia.

It is likely that the medications associated with worse sleep quality are markers for underlying comorbidities including depression, anxiety, and Parkinson's disease, which may worsen sleep quality. The issue of sleep quality and medications in COPD has been extensively considered. ${ }^{7}$ Subjects receiving opioids had worse sleep, pointing to the need to assess pain as a source of sleep difficulties in this population. On the other hand, opioids are associated with sleep disordered breathing, which could have affected sleep. ${ }^{22}$ Use of hypnotics was associated with worse sleep quality. We cannot determine from the data whether this is a drug effect or whether administration of the drug is a marker for the insomnia associated with a major medical

Table 5 Exacerbation data

\begin{tabular}{|c|c|c|c|c|}
\hline Exacerbations & $\begin{array}{l}\text { Good sleep (PSQI } \leq 5) \\
\text { at baseline }(n=5 \mid 3)\end{array}$ & $\begin{array}{l}\text { Poor sleep }(\text { PSQI }>5) \\
\text { at baseline }(n=58 \mathrm{I})\end{array}$ & $\begin{array}{l}\text { Hazard ratio } \\
(95 \% \mathrm{CI})\end{array}$ & $P$-value \\
\hline $\begin{array}{l}\text { Time to first exacerbation } \\
\text { median (days, } 95 \% \mathrm{Cl} \text { ) }\end{array}$ & $239(213-294)$ & $190(159-225)$ & $\begin{array}{l}0.8 I 0(0.697-0.94 I)^{1} \\
0.838(0.720-0.975)^{2} \\
0.889(0.760-1.039)^{3}\end{array}$ & $\begin{array}{l}0.0058^{1} 0.0222^{2} \\
0.1396^{3} \\
\text { Cox proportional }\end{array}$ \\
\hline Rate, mean $\pm S D$ & $\begin{array}{l}\mathrm{I} .37 \pm \mathrm{I} .72 \\
\text { (unadjusted rates) }\end{array}$ & I.70 \pm 2.79 & & $\begin{array}{l}0.0034^{1} \\
0.0107^{2} \\
0.0858^{3} \\
\text { (negative binomial) }\end{array}$ \\
\hline
\end{tabular}

Notes: 'Unadjusted; ${ }^{2}$ adjusted for age and sex; ${ }^{3}$ adjusted for age, sex, neurologic disease, musculoskeletal disease, psychiatric disease, psychiatric medications, anti-seizure medications, opioids, dopaminergics.

Abbreviations: $\mathrm{Cl}$, confidence interval; SD, standard deviation; PSQI, Pittsburgh Sleep Quality Index. 


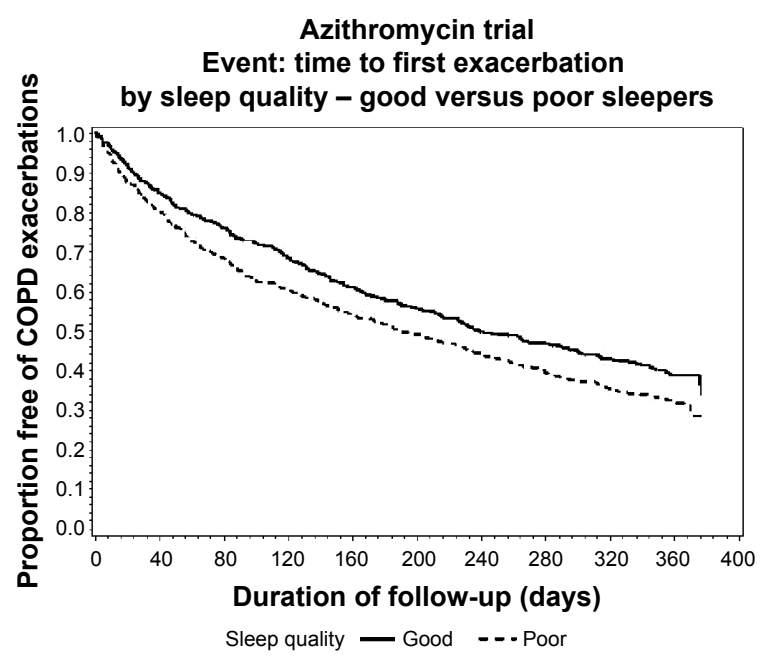

Figure I Time to first exacerbation by sleep quality at baseline in I, II7 patients with moderate to severe chronic obstructive pulmonary disease $(P=0.006)$.

Abbreviation: COPD, chronic obstructive pulmonary disease.

or psychiatric condition. Finally, we did not find that use of oxygen was associated with different sleep quality. This may seem surprising because correction of nocturnal hypoxia would be thought to improve sleep quality. However, while the beneficial effects of nocturnal oxygen on mortality are well established, the effects of nocturnal oxygen on sleep quality have not been extensively studied, and polysomnographic studies of sleep quality with and without oxygen in patients with nocturnal desaturation have yielded conflicting results. ${ }^{23,24}$ Approximately $20 \%$ of our patients reported a diagnosis of obstructive sleep apnea. However, similar to previous findings, ${ }^{6}$ these patients did not report worse sleep quality. One would have expected that patients with sleep apnea would have demonstrated worse sleep quality. However, patients with sleep apnea were not admitted to this study unless they were on treatment and stable. We did not routinely perform polysomnography, and cannot estimate the true incidence of sleep-disordered breathing in our subjects. Recent studies indicate that sleep disordered breathing may be more prevalent in COPD than previously estimated and may be more prevalent that estimated here..$^{25,26}$

\section{Sleep quality and exacerbations}

Good sleep quality at baseline was associated with an increased time to first exacerbation, and decreased exacerbation rate. No difference in mortality was seen between good and poor sleepers. However, the number of deaths was relatively small, and it is possible that there was not sufficient power to detect a difference in mortality. After adjustment for major concomitant medical conditions that themselves could be associated with worsening symptoms, there were no significant differences in time to first exacerbation or exacerbation rate between good and poor sleepers. Similarly, major mental health conditions such as depression ${ }^{27}$ can predict worse clinical course.

It is also possible that poor sleep quality reflects underlying pathophysiologic responses to COPD that would make it more likely that participants will undergo exacerbations or even die. These include secretion of higher levels of proinflammatory cytokines, greater chronic burden of airway pathogens, and undiagnosed sleep disordered breathing. Better sleep quality itself might have a beneficial effect on patients with COPD. Sleep deprivation is known to be a risk factor for a number of adverse health outcomes, including glucose intolerance, hypertension, and cardiovascular disease, ${ }^{28}$ and can lead to worsening airflow obstruction in COPD, ${ }^{29}$ possibly potentiating the tendency for exacerbations.

Finally, respiratory infection is one of the most important causes of exacerbation in COPD. Latent pulmonary aspiration during sleep is a cause of respiratory infection in the elderly. In the "poor sleepers", the use of antidepressants, antipsychotics, anxiolytics, hypnotics, anti-seizure medications, and opioids were significantly more frequent than in the "good sleepers". These medicines may impair laryngeal and cough function during sleep, predisposing to respiratory infections.

\section{Sleep quality and quality of life}

As previously shown, ${ }^{4-7}$ sleep quality was worse with worsening HRQoL and DSQoL. This present study confirms these previous reports using a larger sample of moderate to severely ill patients. Similar to these findings, the PSQI was a predictor of asthma-related quality of life. ${ }^{30}$ Hence, it appears that in patients with obstructive lung disease, sleep quality should be taken into account when interpreting HRQoL and DSQoL.

\section{Limitations}

Sleep quality was assessed by self-report without objective validation. It is possible that estimates of sleep time may be inaccurate in a relatively inactive population where daytime dozing may not be included in sleep time estimates and may influence night-time sleep quality. Future studies should consider objective assessments of sleep quality as well as daytime cognitive function in COPD patients.

\section{Conclusion}

Patients with moderate to severe COPD report a high prevalence of disturbed sleep and poor sleep quality. There is an association between sleep quality and quality of life. Finally, poor sleep 
quality was associated with COPD exacerbations in that poor sleepers had a lower time to first exacerbation. It remains to be determined whether therapy specifically directed at improving sleep can lead to an improved prognosis in COPD.

\section{Acknowledgments}

The present paper is published on behalf of the COPD Clinical Research Network, which is supported by a Cooperative Agreement from the Division of Lung Diseases of the National Heart, Lung, and Blood Institute. This work was funded by the National Institutes of Health. Participants in the COPD Clinical Research Network are as follows:

Brigham and Women's Hospital and affiliated sites (Fallon Clinic, West Roxbury Veterans Hospital)

JJ Reilly Jr (principal investigator), G Washko (co-principal investigator), M Moy, and R Rosiello (investigators), K Allain, V Danilack, B Kniskern, C Mayo, A McDonald, S McQuaid, K Matthess, and S Peterson (coordinators), grant HL074428, General Clinical Research Center (GCRC) grant RR02635.

\section{Denver Health Medical Center and affiliated sites (National Jewish Medical and Research Center, University of Colorado) \\ RK Albert (principal investigator), B Make (co-principal investigator), M Schwarz and C Welsh (investigators), M Gilmartin, C Verano, and J Underwood (coordinators), grant HL074409, GCRC grant RR00051.}

\section{Los Angeles Biomedical Research Institute at Harbor-UCLA Medical Center}

R Casaburi (principal investigator), J Porszasz (investigator), L Diaz, S Ebrahimi, G Garcia, R Love, K Norulak, P Walker, and R Kiledjian (coordinators) grant HL074407, GCRC grant RR00425.

Minnesota Veterans Research Institute, Minneapolis and affiliated sites (Health Partners Research Foundation, Mayo Clinic)

DE Niewoehner (principal investigator), C McEvoy, KR Rice, and PD Scanlon (co-principal investigators), A Fabbrini, J Hart, L Loes, P Neuenfeldt, D Stuber, and C Bourassa (coordinators), grant 1U10-HL074416.

\section{Temple University}

GJ Criner (principal investigator), W Chatila, N Marchetti, A Satti, V Kim, G D’Alonzo, S Krachman, F Cordova,
K Brennan, N Patel, and J Mamary (investigators), H Criner, C Grabianowski, G Jones, N Krayger, and D Fehrle (coordinators), grant HL074408.

\section{University of Alabama at Birmingham}

WC Bailey and JAD Cooper (co-principal investigators), MT Dransfield, LB Gerald, and P O'Reilly (investigators), S Tidwell (coordinator), grant HL074418.

\section{University of California, San Francisco}

SC Lazarus (principal investigator), HA Boushey, and PG Woodruff(investigators), M Birch, R Sakurai, K Schardein, M Dyjak, and C Nguyen (coordinators), grant 1U10HL074431.

\section{University of Maryland, Baltimore}

SM Scharf (principal investigator), M Alattar, P Amelung, M Cowan, J Hanson, J Hasday, A Iacono, C Shanholtz, $\mathrm{N}$ Todd, and A Verceles (investigators), W Bell-Farrell, T Fitzgerald, and P Wood (coordinators), grant HL074441, GCRC grant RR16500.

University of Michigan, Ann Arbor, and affiliated site (Veterans Affairs Medical Center)

FJ Martinez (principal investigator), JL Curtis, MK Han, KR Flaherty, T Standiford, SE Gay, and TE Sisson (investigators), L McCloskey, M Christensen, D Thompson, and D White (coordinators), grant HL074422.

\section{University of Pittsburgh}

F Sciurba (principal investigator), J Bon (investigator), D Filippino, L Lane, M Pitaro, L Kniolek, and R Folger (coordinators), grant HL074439, GCRC grant RR00056.

\section{University of Minnesota (Data Coordinating Center)} JE Connett (principal investigator), NR Anthonisen (steering committee chair), C Wendt (co-principal investigator), M Skeans, W Patrek, H Voelker, and S Harnden (coordinators), grant 1U10-HL074424.

\section{Data and Safety Monitoring Board}

BB Bender, C Champlin, SF Kelsey, JR Landis, B Phillips, GM Turino, R Veatch, A Waldo, and A Wanner.

\section{Protocol Review Committee}

HW Kelly, J Maurer AJ McSweeny, RM Senior, EA Thom, PD Wagner, and RL ZuWallack. 


\section{National Heart, Lung, and Blood Institute}

G Weinmann (Deputy Director, Division of Lung Diseases), T Croxton (Director, Airway Biology and Disease Program), A Punturieri (program officer), MP Stylianou (biostatistician).

\section{Author contributions}

JG-B had full access to all the data reported in this paper and takes responsibility for the data and accuracy of the data analysis. SMS takes responsibility for the integrity of the submission as a whole, from inception to published article. SK, CEM, JCC, RKA, and GJC assisted in drafting the manuscript and interpreting the data. Ms Lindberg and JCC substantially participated in the analysis of these data and take responsibility for the integrity of the data. All of the authors confirm that the study objectives and procedures are honestly disclosed, and that the results are valid and generalizable to the population similar to those enrolled in this study.

\section{Disclosure}

None of the authors have a conflict of interest that could affect this manuscript.

\section{References}

1. Hajiro T, Nishimura K, Tsukino Ikeda A, Oga T, Izumi T. A comparison of the level of dyspnea vs disease severity in indicating the health-related quality of life of participants with COPD. Chest. 1999;116(6): 1632-1637.

2. Schlecht NF, Schwartzman K, Bourbeau J. Dyspnea as clinical indicator in participants with chronic obstructive pulmonary disease. Chron Respir Dis. 2005;2(4):183-191.

3. Mahler DA, Faryniarz K, Tomlinson D, et al. Impact of dyspnea and physiologic function on general health status in participants with chronic obstructive pulmonary disease. Chest. 1992;102(2):395-401.

4. Nunes DM, Mota RMS, de Pontes Neto OL, Pereira ED, de Bruin VM, de Bruin PF. Impaired sleep reduces quality of life in chronic obstructive pulmonary disease. Lung. 2009;187(3):159-163.

5. McSharry DG, Ryan S, Calverley P, Edwards JC, McNicholas WT. Sleep quality in chronic obstructive pulmonary disease. Respirology. 2012;17(7):1119-1124.

6. Scharf SM, Maimon N, Simon-Tuval T, Bernhard-Scharf BJ, Reuveni H, Tarasiuk A. Sleep quality predicts quality of life in chronic obstructive pulmonary disease. Int J Chron Obstruct Pulmon Dis. 2010;6:1-12.

7. Krachman S, Minai O, Scharf SM. Sleep abnormalities and treatment in emphysema. Proc Am Thorac Soc. 2008;5(4):536-542.

8. Agusti A, Hedner J, Marin JM, Barbé F, Cazzola M, Rennard S. Nighttime symptoms: a forgotten dimension of COPD. Eur Respir Rev. 2011;20(121):183-194.

9. Tsai CL, Brenner BE, Camargo CA Jr. Circadian-rhythm differences among emergency department participants with chronic obstructive pulmonary disease exacerbation. Chronobiol Int. 2007;24(4):699-713.

10. Kwon JS, Wolfe LF, Lu BS, Kalhan R. Hyperinflation is associated with lower sleep efficiency in COPD with co-existent obstructive sleep apnea. COPD. 2009;6(6):441-445.
11. McNicholas WT, Verbraeken J, Marin JM. Sleep disorders in COPD: the forgotten dimension. Eur Respir Rev. 2013;22(129):365-375.

12. Omachi TA, Blanc PD, Claman DM, et al. Disturbed sleep among COPD patients is longitudinally associated with mortality and adverse COPD outcomes. Sleep Med. 2012;13(5):476-483.

13. Kent BD, McNicholas WT, Verbraecken J. Disturbed sleep and COPD outcomes: cart meets horse. Sleep Med. 2012;13(5):453-454.

14. Albert RK, Connett J, Bailey WC, et al. Azithromycin for prevention of COPD exacerbations. N Engl J Med. 2011;365(8):689-698.

15. Buysse DJ, Reynolds CF 3rd, Monk TH, Berman SR, Kupfer DJ. The Pittsburgh Sleep Quality Index: a new instrument for psychiatric practice and research. Psychiatry Res. 1989;28(2):192-213.

16. Strategy for the Diagnosis, Management and Prevention of COPD. Initiative for Chronic Obstructive Lung Disease (GOLD) 2011. Available from: http://www.goldcopd.org/. Accessed January 7, 2015.

17. WHO Collaborating Centre for Drug Statistics Methodology. Guidelines for ATC classification and DDD assignment 2013. Oslo, Norway: World Health Organization; 2010. Available from: http://www.whocc. no/filearchive/publications/1_2013guidelines.pdf. Accessed January 7, 2015.

18. Niewoehner DE, Rice K, Cote C, et al. Prevention of exacerbations of chronic obstructive pulmonary disease with tiotropium, a once-daily inhaled anticholinergic bronchodilator: a randomized trial. Ann Intern Med. 2005;143(5):317-326.

19. Ware JE Jr, Sherbourne CD. The MOS 36-item Short Form Health Survey (SF-36): I. Conceptual framework and item selection. Med Care. 1992;30(6):473-483.

20. Jones PW, Quirk FH, Baveystock CM, Littlejohns P. A self-complete measure of health status for chronic airflow limitation: the St George's Respiratory Questionnaire. Am Rev Respir Dis. 1992;145(6): 1321-1327.

21. Meguro M, Barley EA, Spencer S, Jones PW. Development and validation of an improved, COPD-specific version of the Saint George's Respiratory Questionnaire. Chest. 2007;132(2):456-463.

22. Alattar M, Scharf SM. Opioid associated central sleep apnea. Sleep Breath. 2009;13(2):201-206.

23. Calverly PM, Brezinova V, Douglas NJ, Catterall JR, Flenley DC. The effect of oxygenation on sleep quality in chronic bronchitis and emphysema. Am Rev Respir Dis. 1982;126(2):206-210.

24. Fleetham J, West P, Mezon B, Conway W, Roth T, Kryger M. Sleep, arousals, and oxygen desaturation in chronic obstructive pulmonary disease. The effect of oxygen therapy. Am Rev Respir Dis. 1982;126(3): 429-433.

25. Romem A, Iacono A, McIlmoyle E, et al. Obstructive sleep apnea in participants with end-stage lung disease. J Clin Sleep Med. 2013; 9(7):687-693.

26. Greenberg-Dotan S, Reuveni H, Tal A, et al. Increased prevalence of obstructive lung disease in participants with obstructive sleep apnea. Sleep Breath. 2014;18(1):69-75.

27. Omachi TA, Katz PP, Yelin EH, et al. Depression and health-related quality of life in chronic obstructive pulmonary disease. Am J Med. 2009;122(8):778.e9-e15.

28. Czeisler CA. Impact of sleepiness and sleep deficiency on public health - utility of biomarkers. J Clin Sleep Med. 2011;7(5 Suppl): S6-S8.

29. Phillips BA, Cooper KR, Burke TV. The effect of sleep loss on breathing in chronic obstructive pulmonary disease. Chest. 1967;91(1): $29-32$.

30. Mastronarde JG, Wise RA, Shade DM, Colopade CO, Scharf SM. Sleep quality in asthma: results of a large prospective clinical trial. J Asthma. 2008;45(3):183-189. 
International Journal of COPD

\section{Publish your work in this journal}

The International Journal of COPD is an international, peer-reviewed journal of therapeutics and pharmacology focusing on concise rapid reporting of clinical studies and reviews in COPD. Special focus is given to the pathophysiological processes underlying the disease, intervention programs, patient focused education, and self management protocols.

This journal is indexed on PubMed Central, MedLine and CAS. The manuscript management system is completely online and includes a very quick and fair peer-review system, which is all easy to use. Visit http://www.dovepress.com/testimonials.php to read real quotes from published authors 